\title{
Incorrectly Positioned Precordial Electrodes by ECG Finding
}

National Cancer Institute

\section{Source}

National Cancer Institute. Incorrectly Positioned Precordial Electrodes by ECG Finding. NCI Thesaurus. Code C114160.

An electrocardiog raphic recording in which one or more precordial electrodes are placed incorrectly with respect to the standard chest electrode positions resulting in improper representation of the affected leads. (CDISC) 